\title{
A randomized, 12-month controlled trial to evaluate non-inferiority of early compared to conventional loading of modSLA implants in single tooth gaps
}

\author{
Michel Dard ${ }^{1}$, Makoto Shiota ${ }^{2,5^{*}}$, Minoru Sanda ${ }^{2}$, Yasutomo Yajima ${ }^{3}$. Hideshi Sekine ${ }^{4}$ and Shohei Kasugai ${ }^{2}$
}

\begin{abstract}
Background: The aim of the study was to evaluate whether early loading of implants with a chemically modified sandblasted, large-grit, acid-etched (SLA) (SLActive ${ }^{\oplus}$ ) surface was non-inferior to conventional loading in terms of change in crestal bone level.

Methods: This was a randomized, controlled, multicenter study. Patients requiring single-tooth rehabilitation in the posterior maxilla or mandible received implants and were randomized to receive a provisional restoration in occlusal load after $25 \pm 3$ days (early loading) or after $13 \pm 1$ weeks (conventional loading). The primary endpoint was change in crestal bone level between implant placement (baseline) and 6 months. Secondary endpoints included change in crestal bone level between baseline and 12 months, implant survival and success rates, and patient satisfaction.

Results: Of the 84 patients enrolled, 78 received implants and were randomized onto the early loading (41 patients) and conventional loading (37 patients) groups. The mean change in crestal bone level between baseline and 6 months was $0.56 \pm 0.58$ and $0.51 \pm 0.62 \mathrm{~mm}$ for early and conventional loading, respectively; at 12 months, the mean change was $0.76 \pm 0.60$ and $0.73 \pm 0.77 \mathrm{~mm}$, respectively. Implant survival and success at 12 months were $100 \%$ for both groups. Patient satisfaction was similar between the groups, except that more patients in the early loading group were satisfied or highly satisfied with the time taken for fitting.

Conclusion: The study demonstrated that early implant loading was non-inferior to conventional implant loading in terms of crestal bone level change in a Japanese patient population in short follow-up period and single tooth gaps in molar regions.
\end{abstract}

Keywords: Early loading, Conventional loading, Non-inferiority, Crestal bone level, Maxilla, Mandible

\section{Background}

The use of dental implants to replace missing or compromised teeth has been well documented clinically over many years. High implant survival rates have been demonstrated for over 10 [1-3], 15 [4], and 20 years [5, 6]. Long-term survival rates for single-tooth implants have been shown to be greater than those for tooth-supported restorations, e.g., fixed partial dentures (FPDs) [7, 8]. Good long-term survival

\footnotetext{
* Correspondence: mshiota.impl@tmd.ac.jp

${ }^{2}$ Tokyo Medical and Dental University, Tokyo, Japan

${ }^{5}$ Department of Oral Implantology and Regenerative Dental Medicine, Tokyo Medical and Dental University, 1-5-45 Yushima, Bunkyo-ku, Tokyo 113-8549, Japan

Full list of author information is available at the end of the article
}

rates have also been observed in the posterior regions of the jaws, i.e., in premolar and molar regions $[1,9,10]$.

The conventional protocol for loading of rough-surfaced dental implants, i.e., placement of the prosthetic crown, recommends undisturbed healing after surgery for 3 months in the mandible and $4-6$ months in the maxilla $[11,12]$ to allow the osseointegration process to take place. However, it would be beneficial if the healing period could be shortened without jeopardizing implant success [13]. Earlier implant loading protocols, e.g., loading after 3-4 weeks, have therefore been investigated. Such protocols may also have advantages in terms of preservation of the soft and hard tissues [14]. Early loading has also shown equivalence to conventional loading in terms of the amount of marginal 
peri-implant bone loss $[12,15]$ or implant or prosthesis failure [12]. Similar outcomes have also been demonstrated between early and conventional loading in the first molar region in the maxilla and mandible [16].

Early loading still requires osseointegration to take place. Implant surfaces have therefore been developed to try to speed up the osseointegration process. Some of these implant surface modifications have included alteration of the surface features to produce micro-rough, micro-porous, or nano-rough surface topography [17-19] or biochemical modification through impregnation, coating, or processing [20-22].

One of the more clinically successful implant surface modifications in recent years was the chemical modification of the sandblasted, large-grit, acid-etched (SLA) surface to produce the hydrophilic SLActive ${ }^{\bullet}$ surface (Straumann AG, Basel, Switzerland). It is accomplished by rinsing the titanium surface after the etching process under nitrogen protection and continuous storage in an isotonic $\mathrm{NaCl}$ solution that prevent deposition of carbon compounds. Preclinical data have demonstrated significantly greater bone-to-implant contact [23-25], bone fill [26], and removal torque [27] with the modified SLA surface compared to conventional SLA. Earlier osseointegration has also been demonstrated histologically [28-30]. Clinical results have shown greater implant stability [31] and an earlier shift from decreasing to increasing implant stability after placement [32]. The original SLA surface allowed the implant restoration time to be reduced from 12 to 6 weeks [33, 34]; the properties of the chemically modified SLA surface allow this time to be further reduced to 3-4 weeks. Early loading with these implants has been demonstrated in a number of clinical trials [35-38].

Early loading protocols have become relatively common procedures in many countries for implant restoration, but the procedure is much less common in Japan. The purpose of this study, therefore, was to investigate whether the chemically modified SLA implant with early loading was non-inferior to conventional loading, based on the amount of crestal bone change between baseline and 6 months after surgery (Fig. 1).

\section{Methods}

This study was designed as a randomized, controlled, multicenter clinical trial to evaluate non-inferiority of early loading compared to conventional loading of dental implants with a chemically modified SLA surface placed in single tooth gaps, involving three centers in Japan (Tokyo Medical and Dental University (TMDU), Tokyo Dental College Chiba Hospital (TDCC), and Tokyo Dental College Suidobashi Hospital (TDCS)). The study was conducted in accordance with the Declaration of Helsinki (1964 and all subsequent amendments), the Japanese Pharmaceutical Affairs Law, the Ordinance Concerning the Standards for Clinical Trials on Medical Devices (2005 MHLW Ordinance No. 36), and the relevant notifications and protocol. The study was approved by the Institutional Review Boards of the medical institutions involved. Written informed consent was obtained from all patients. The study was registered at www.clinicaltrials.gov.

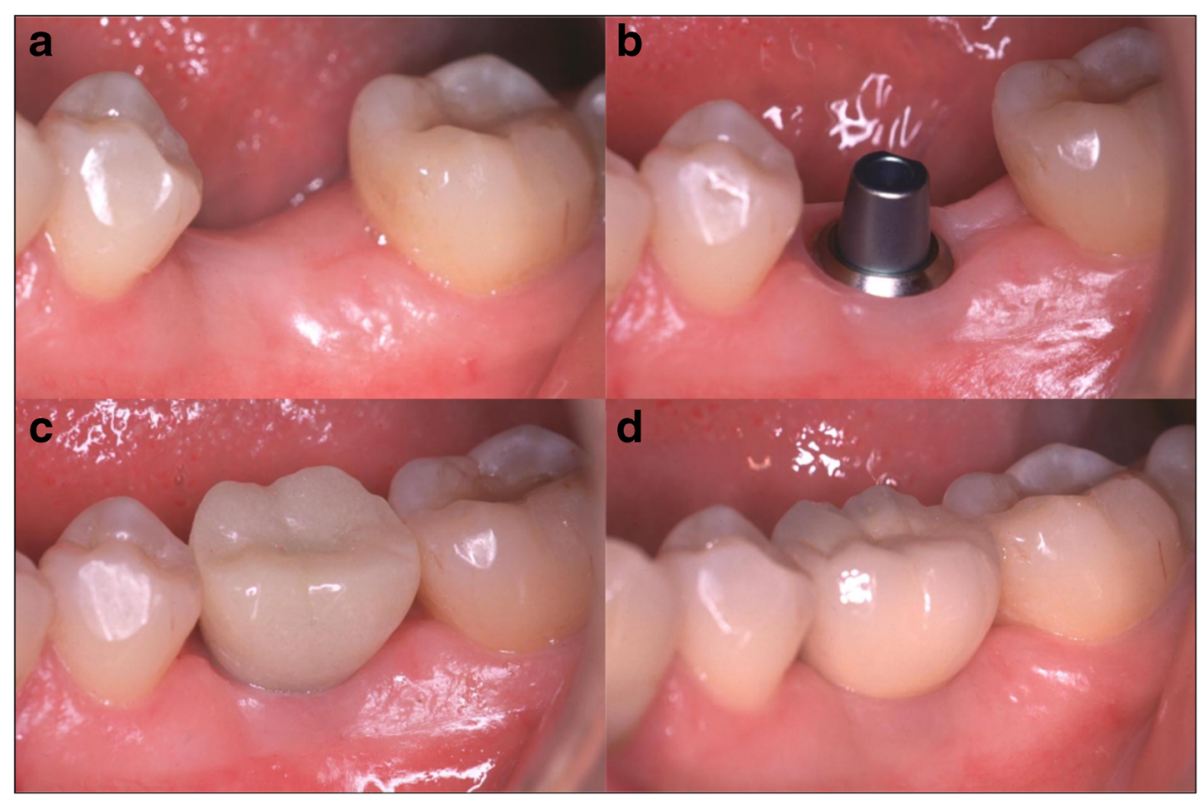

Fig. 1 Clinical pictures in each procedure. a Before implant placement. b After abutment connection. c Temporary prosthesis. $\mathbf{d}$ Final prosthesis 
Table 1 Inclusion criteria and exclusion criteria

\begin{tabular}{ll}
\hline Inclusion criteria & Age over 20 \\
& Patient who have missing teeth in premolar or \\
& molar site \\
& Good oral hygiene \\
& Predicted implant site has 1-3 quality of bone density \\
& and enough quantity of bone \\
& Extraction socket in predicted implant site is \\
& completely healed (16 weeks or more) \\
Exclusion criteria & Systemic condition negatively affect implant treatment \\
& (e.g., septicemia, immune deficiency, diabetes) \\
& Systemic condition that contraindicate oral surgical \\
& procedure \\
& Patient with ten or more cigarette consumption in a day \\
& Patient who is going to participate in another clinical \\
& trial or already joined within 30 days before agreement \\
& of this trial \\
& Patient who do not follow and cooperative dentist's \\
& instruction \\
& Pregnant or lactating female or female who might have \\
& willingness to be pregnant \\
& Patient who has caries or severe periodontal disease \\
& Severe parafunction of bruxism or clenching \\
& Antagonist of expected implant site is removable partial \\
denture or edentulous site without prosthesis \\
Patient with poor oral hygiene or not positive for \\
plaque control \\
Patient have adjacent teeth next to the edentulous site \\
with periodontal pocket of 4 mm or more \\
Cases needs bone augmentation procedure \\
History of implant failure at the same site
\end{tabular}

\section{Patients}

Patients were enrolled according to strict pre-defined inclusion and exclusion criteria. The most important inclusion criteria were as follows: age $\geq 20$ years, single tooth gaps in molar or premolar in the mandible or maxilla, bone quality I-III and sufficient bone quantity to allow implant placement, and substantially healed extraction sockets (at least 16 weeks after tooth extraction).

Important exclusion criteria fell into two categories: systemic and dental. The most important systemic exclusion criteria were as follows: systemic disease, e.g., diabetes mellitus; serious internal medical problems, e.g., cardiac or cerebral infarction; bone disorders, e.g., metabolic bone disease, temporomandibular joint disorders, treatable changes in the oral mucosa, local root remnants, xerostomia, and bisphosphonate medication; inadequate wound healing capacity, prolonged therapy-resistant functional disorders, and steroid use or irradiation; uncontrolled bleeding disorders and anticoagulation drugs/hemorrhagic diatheses; psychoses, drug or alcohol abuse, or titanium allergy (based on patient declaration); smoking >10 cigarettes per day; pregnancy and/or breastfeeding; participation in another clinical trial during or within 30 days before this trial; unwillingness or inability to follow the investigator's instructions; or any other conditions that might prevent study completion in the opinion of the investigator. The dental exclusion criteria were as follows: untreated dental and serious periodontal lesions; severe bruxism or clenching habits; existing implants in the adjacent position; removable dentures or un-restored tooth gaps in the opposing dentition; probing pocket depth $\geq 4 \mathrm{~mm}$ at a tooth immediately adjacent to the dental implant site; major simultaneous augmentation procedures; requirement for maxillary sinus lift, socket preservation, or ridge augmentation; and failure of a previous implant at the planned implant site (Table 1).

When a patient fulfilled all inclusion criteria and had no exclusion criteria, then he/she got implant surgery and checked the condition met first criteria for loading (loading criteria 1 (LC1)) (Table 2).

\section{Implants}

All patients received Ti grade IV Straumann Standard Plus Regular Neck (SP RN) implants, $4.1 \mathrm{~mm}$ in diameter and 8,10 , or $12 \mathrm{~mm}$ in length, with SLActive ${ }^{\bullet}$ surface (Institut Straumann AG, Basel, Switzerland).

\section{Randomization}

Patients fulfilling the necessary criteria were randomized to the early loading arm (implant loading after $25 \pm$ 3 days) or conventional loading arm (implant loading after $13 \pm 1$ weeks). The initial randomization sequence was created after implant surgery once the previously defined LC1 had been met, by means of variable block sizes in order to avoid disproportionate allocation within early loading or conventional loading groups [39]. Lists

Table 2 Loading criteria applied at implant placement surgery (loading criteria 1 (LC1)) and attachment of provisional restoration (loading criteria 2 (LC2))

\begin{tabular}{|c|c|}
\hline Loading criteria 1 & Loading criteria 2 \\
\hline $\begin{array}{l}\text { - Sufficient oral hygiene } \\
\text { - At least } 1 \mathrm{~mm} \text { bone volume around the implant }{ }^{a} \\
\text { - No major dehiscence }(<3 \mathrm{~mm} \text { ) or other bone defects at the implant site } \\
\text { - Bone quality I-III } \\
\text { - Adequate insertion torque ( } \geq 15 \mathrm{Ncm} \text { during placement of the healing cap) } \\
\text { - Suitable implant position } \\
\text { - Dental radiograph shows three threads of implant fixture }\end{array}$ & $\begin{array}{l}\text { - Sufficient oral hygiene } \\
\text { - No rotational movement of the implant }{ }^{\text {b }} \text { during abutment } \\
\text { connection at } 15 \mathrm{Ncm} \\
\text { - No moderate or severe pain at the implant site during } \\
\text { abutment connection at } 15 \mathrm{Ncm} \\
\text { - Suitable implant position } \\
\text { - Dental radiograph shows three threads of implant fixture }\end{array}$ \\
\hline
\end{tabular}

Any patients not fulfilling LC1 received an alternative treatment, e.g., bridge, false teeth, and were subsequently included in the safety analysis set (SAS)

${ }^{a}$ That is, for a $4.1-\mathrm{mm}$ diameter 10-mm-long implant, crestal width and bone height should be 6.1 and $11 \mathrm{~mm}$, respectively

${ }^{\mathrm{b}}$ During abutment connection 
were prepared by an independent statistician and were centrally controlled by a third party who was not involved in the study. All patients who fulfilled LC1 were included in the full analysis set (FAS). If patients did not fulfill LC1, they received an alternative treatment, e.g., bridge, false teeth, or treatment by other implant, and were subsequently included and evaluated in the safety analysis set (SAS).

Loading criteria were evaluated once more (loading criteria 2 (LC2); Table 2) at the time of provisional restoration delivery at $25 \pm 3$ days after surgery in the early loading arm and at $13 \pm 1$ weeks after surgery in the conventional loading arm (Fig. 2). Patients fulfilling the LC2 criteria were included in the per protocol set (PPS). If patients did not fulfill LC2 (i.e., due to an unstable implant or moderate to severe pain), they received an alternative treatment and were included in the FAS. All patients receiving an implant were therefore included in the FAS irrespective of whether they fulfilled LC2.

\section{Surgical and restoration procedure}

There were six evaluation time points from recruitment to study completion with a variety of safety and efficacy data obtained at each time point, including primary and secondary endpoint data. The day of implant surgery (day 0) was the baseline time point; patient consent and screening procedures were performed between 8 weeks and 1 day before day 0 . Implant surgery and placement were performed according to the manufacturer's recommended guidelines. All implants were placed in the alveolar ridge that had healed for at least 16 weeks after tooth extraction. Sutures were removed 7-14 days after surgery. In both arms, ready-made abutments for cement retention were connected at $15 \mathrm{Ncm}$ and implants were loaded through temporary crown. The occlusal contacts were equivalated as holding a 21- $\mu \mathrm{m}$ AccuFilm II (Parkell Inc, Edgewood, NY, USA) when patients bite heavily. Final crowns were placed 6 months after implant placement in both groups, with the same abutment for the temporary crown, and it was tightened at the torque of $35 \mathrm{Ncm}$. Patients were recalled for a follow-up evaluation 12 months after surgery.

\section{Efficacy evaluations}

The primary endpoint was a change of crestal bone level between implant surgery (baseline) and final restoration (6 months), assessed by measuring the distance from the implant shoulder to the first bone-to-implant contact both mesially and distally to the implant.

Bone level was measured by a single reader on standardized periapical radiographs taken at baseline (day 0), suture removal (7-14 days after surgery), provisional
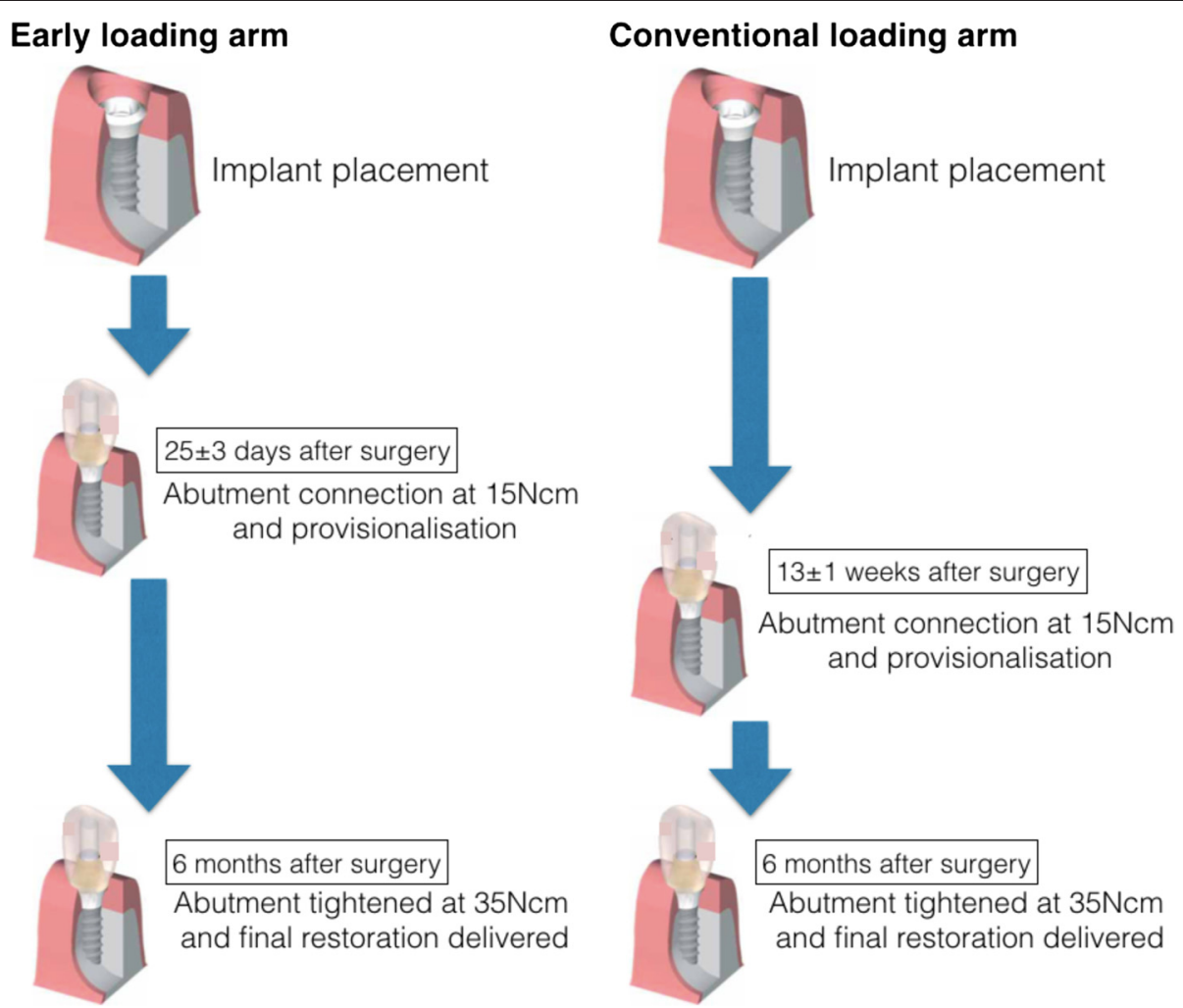

Fig. 2 Restorative flow diagram 
restoration, final restoration, and at the 12-month follow-up. Radiographs were standardized by using customized film holders. A commercially available film holder was employed (e.g., System (Dentsply Rinn, Elgin, IL, USA)), RWT ${ }^{\bullet}$ window $x$-ray system (KentzlerKaschner Dental, Ellwangen, Germany) or similar). The film was placed almost parallel to the implants. Indentations of the incisal edge of the implant and of the neighboring teeth (where possible) were taken with impression material to improve reproducibility. The customized radiographic holder was fabricated by putting autopolymerizing resin to the biting plate of the film holder and adapted its shape to the patient dentition in order to standardize the position of the X-ray film. The radiograph was exposed once the resin had polymerized, and the stent removed and stored for future use.

Secondary endpoints included implant survival and success rates, changes in crestal bone level between baseline and 12 months, and patient satisfaction. Implant success and survival were assessed at suture removal, provisional restoration, final restoration, and at the 12-month follow-up. Implant survival was defined as remaining of implant, and implant success was defined according the criteria by Buser et al. [40], i.e., absence of pain, foreign body discomfort or dysesthesia, absence of recurrent peri-implant infection with suppuration, absence of implant mobility, and absence of continuous peri-implant radiolucency.

Patient satisfaction was evaluated at the final restoration and 12-month follow-up visits by asking the patients to rate their assessment of six parameters: prosthesis comfort, appearance, ability to chew, ability to taste, general satisfaction, and patients substantial feeling for adaptation. Patients rated their assessment on a five-point scale (highly satisfied, satisfied, no opinion, dissatisfied, highly dissatisfied).

In addition, periodontal examination, in the form of probing depth (PD) and bleeding on probing (BoP), was performed at pre-screening and at the 12-month follow-up.

\section{Statistical analysis}

Descriptive summary statistics were computed for all parameters, and quantitative parameters were described using mean, standard deviation, median, quartiles, minimum, and maximum. For qualitative variables, absolute and relative frequencies were given. All descriptions were done separately for treatment groups and visits.

The hypothesis was that the change in crestal bone level between baseline and 6 months would be noninferior for early loading compared to conventional loading. Non-inferiority was defined as a clinically relevant difference of up to $0.3 \mathrm{~mm}$ because in the same type of study by Bornstein et al. [35], most implants demonstrated 0.0 to $0.3 \mathrm{~mm}$ after 3 years of observation period, and it did not reach statistical significance. The null hypothesis (H0) was therefore that the mean crestal bone loss is $>0.3 \mathrm{~mm}$ higher with early loading compared to conventional loading. The hypothesis was tested by calculating whether the difference of crestal bone loss was within $0.3 \mathrm{~mm}$ between conventional loading and early loading at 6 months $(p<0.05)$.

\section{Analysis data set}

There were three types of data sets used: PPS, FAS, and SAS. The SAS included all patients who got implant treatment, including patients who did not meet LC1 and evacuated before randomization. The FAS included all patients who received an implant and who had at least one post-randomization measurement, irrespective of any premature termination or major protocol violations; this set therefore includes the PPS. The PPS includes all patients who completed the study with no major protocol violations.

Based on a two-group one-sided $t$ test with significance level of 0.025 , a sample size of 29 patients per group was calculated to have $80 \%$ power to reject the null hypothesis, assuming an expected difference in means of 0 , a common standard deviation of 0.4 , and a non-inferiority lower limit of $0.3 \mathrm{~mm}$. A subject dropout rate of $20 \%$ was assumed, giving a sample size of 37 patients per group (total of 74 patients). Calculations were made using nQuery Advisor 6.01.

\section{Results}

\section{Patients}

The study enrolled 84 Japanese patients who had single missing tooth in the molar region. Since four patients were withdrawn due to the exclusion criteria (systemic disease, adjacent teeth with probing pocket depth deeper than $4 \mathrm{~mm}$, mental disorder, and bone deficiency, respectively), 80 patients underwent implant placement. Two further patients were withdrawn before randomization because the insertion torque did not reach the $15 \mathrm{Ncm}$ in the surgery which was one of the requirements for LC1. Of the 78 who participated in the study, 41 were allocated to the early loading arm. Three patients were withdrawn because implants in two patients lost their osseointegration to the alveolar bone and the other one an X-ray picture did not include three threads that had to be included for evaluation. Thirty seven patients were allocated to the conventional loading arm. The pregnancy was detected to one patient in the conventional loading arm, and she was excluded from the PPS and FAS. The full participant flow diagram is shown in Fig. 3.

The mean age at implant surgery in the PPS was $47.0 \pm 14.5$ years. Patient demographic data are shown in Table 3. The first patients were recruited in December 2010, and the final examination was performed in August 


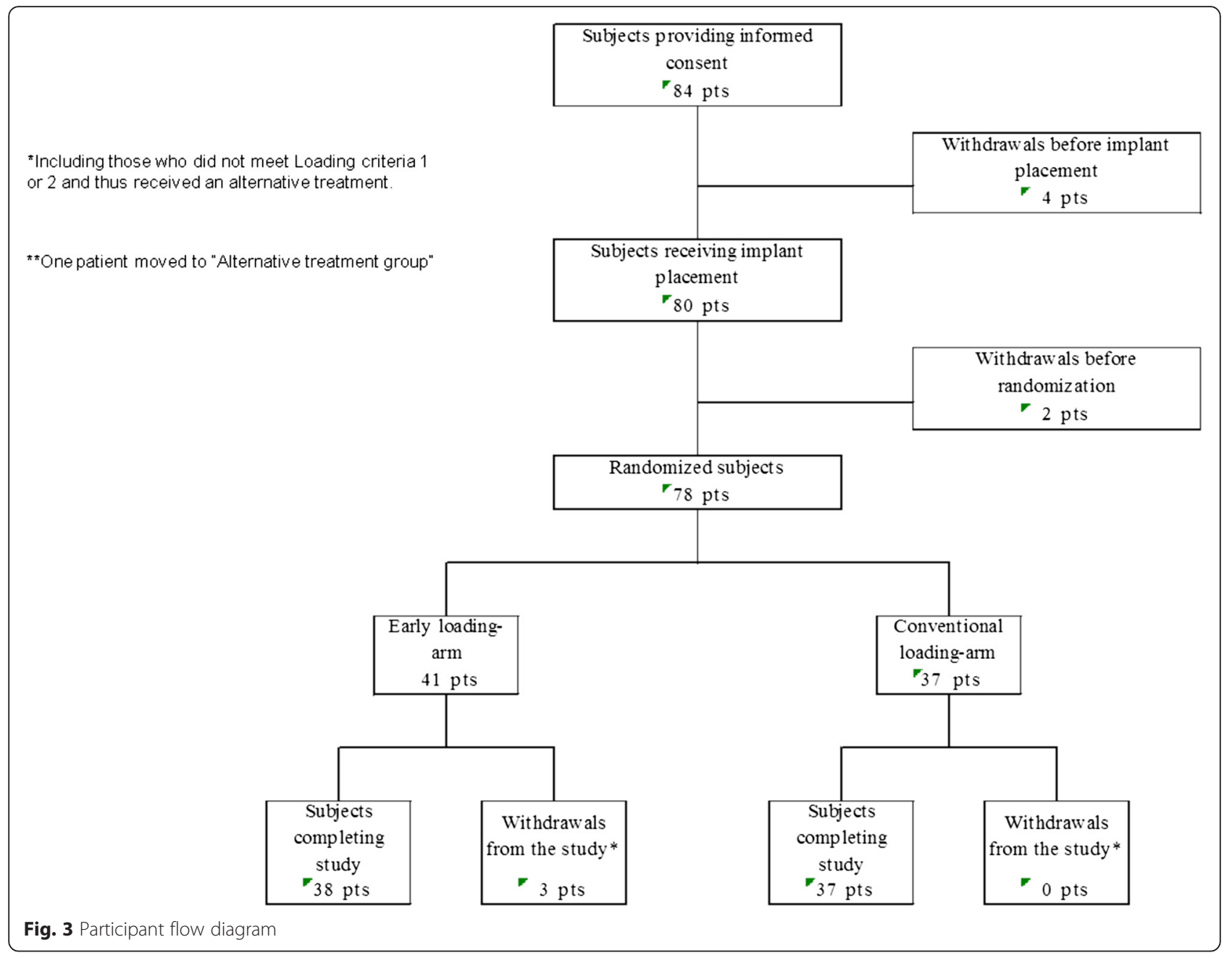

2012. No methodological changes were made after commencement of the trial.

\section{Efficacy evaluations: bone level changes}

The mean change in crestal bone level in the PPS 6 months after implant placement was $0.56 \pm 0.58$ and $0.51 \pm 0.62 \mathrm{~mm}$ in the early and conventional loading arms, respectively, while at 12 months, it was $0.76 \pm 0.60$ and $0.73 \pm 0.77 \mathrm{~mm}$, respectively (Table 4 and Fig. 4). The inter-arm differences in the means between the early and conventional loading arms 6 and 12 months after implant placement were 0.048 (95\% CI -0.227-0.322) and $0.026 \mathrm{~mm}$ (95\% CI $-0.293-0.346)$, respectively. Noninferiority, defined as crestal bone level change between the treatment arms of $\leq 0.3 \mathrm{~mm}$, was therefore confirmed. The mean change in crestal bone level in the FAS 6 months after implant placement was $0.56 \pm 0.58$ and $0.51 \pm 0.62 \mathrm{~mm}$ in the early and conventional loading arms, respectively, while at 12 months, it was $0.78 \pm 0.61$ and $0.73 \pm 0.77 \mathrm{~mm}$, respectively. The inter-arm differences in the means between the treatment arms in FAS 6 and 12 months after implant placement were 0.048 (95\%

Table 3 Patient demographics and other baseline characteristics (PPS)

\begin{tabular}{lllll}
\hline Characteristics & & $\begin{array}{l}\text { Early loading arm } \\
(N=38)\end{array}$ & $\begin{array}{l}\text { Conventional loading arm } \\
(N=37)\end{array}$ & 75 \\
\hline Age & No. of patients & 38 & 37 & $75)$ \\
& Mean & 46.6 & 47.4 & 47.0 \\
& SD & 13.2 & 16.0 & 14.5 \\
Gender & Male & $5(13.2)$ & $19(51.4)$ & 24 (32.0) \\
& Female & $33(86.8)$ & $18(48.6)$ & $51(68.0)$ \\
\hline
\end{tabular}


Table 4 Mean crestal bone level changes, in early loading and conventional loading arms (PPS), 6 months after implant placement

\begin{tabular}{|c|c|c|c|c|c|c|}
\hline Treatment arm & Summary statistics & Baseline & 6 months & $\begin{array}{l}\text { Change from baseline } \\
\text { to } 6 \text { months }\end{array}$ & 12 months & $\begin{array}{l}\text { Change from baseline } \\
\text { to } 12 \text { months }\end{array}$ \\
\hline \multirow[t]{7}{*}{ Early loading-arm $(N=38)$} & No. of patients & 38 & 38 & 38 & 38 & 38 \\
\hline & Mean (SD) & $1.342(0.600)$ & $1.903(0.603)$ & $0.561^{\mathrm{a}}(0.576)$ & $2.102(0.483)$ & $0.760^{\mathrm{b}}(0.603)$ \\
\hline & Maximum & 2.73 & 2.96 & 2.21 & 3.47 & 2.15 \\
\hline & Third quartile & 1.73 & 2.22 & 0.88 & 2.34 & 1.14 \\
\hline & Median & 1.25 & 2.015 & 0.55 & 2.05 & 0.80 \\
\hline & First quartile & 0.98 & 1.52 & 0.17 & 1.77 & 0.37 \\
\hline & Minimum & 0.29 & 0.48 & -0.51 & 1.24 & -0.39 \\
\hline \multirow[t]{7}{*}{ Conventional loading arm $(N=37)$} & No. of patients & 37 & 37 & 37 & 36 & 36 \\
\hline & Mean (SD) & $1.355(0.724)$ & $1.868(0.521)$ & $0.513^{\mathrm{b}}(0.617)$ & $2.099(0.558)$ & $0.734^{\mathrm{b}}(0.77)$ \\
\hline & Maximum & 3.01 & 3.81 & 1.82 & 3.74 & 2.54 \\
\hline & Third quartile & 1.85 & 2.07 & 0.94 & 2.45 & 1.185 \\
\hline & Median & 1.43 & 1.83 & 0.49 & 2.02 & 0.61 \\
\hline & First quartile & 0.76 & 1.58 & 0.07 & 1.735 & 0.14 \\
\hline & Minimum & 0.27 & 0.83 & -0.71 & 1.04 & -0.66 \\
\hline
\end{tabular}

Inter-arm difference (6 months): difference in mean $95 \%$ confidence interval 0.048 (-0.227-0.322)

${ }^{b}$ Inter-arm difference (6 months): difference in mean $95 \%$ confidence interval $0.026(-0.293-0.346)$

CI -0.227-0.322) and 0.045 (95 \% CI $-0.271-0.362$ ), respectively.

\section{Efficacy evaluations: implant survival and success rates}

In the PPS and FAS, the implant survival rate was $100 \%$ after 12 months. In the PPS, the implant success rate was $100 \%$ at all time points in both the conventional and early loading arms; however, in the FAS, the success rate in the conventional loading arm was $100 \%$ at all time points, while in the early loading arm, success was $100 \%$ at suture removal at 12-month follow-up and $95 \%$ at the final restoration time point (6 months). This was because two patients were excluded from FAS because the insertion torque did not reach $15 \mathrm{Ncm}$ and

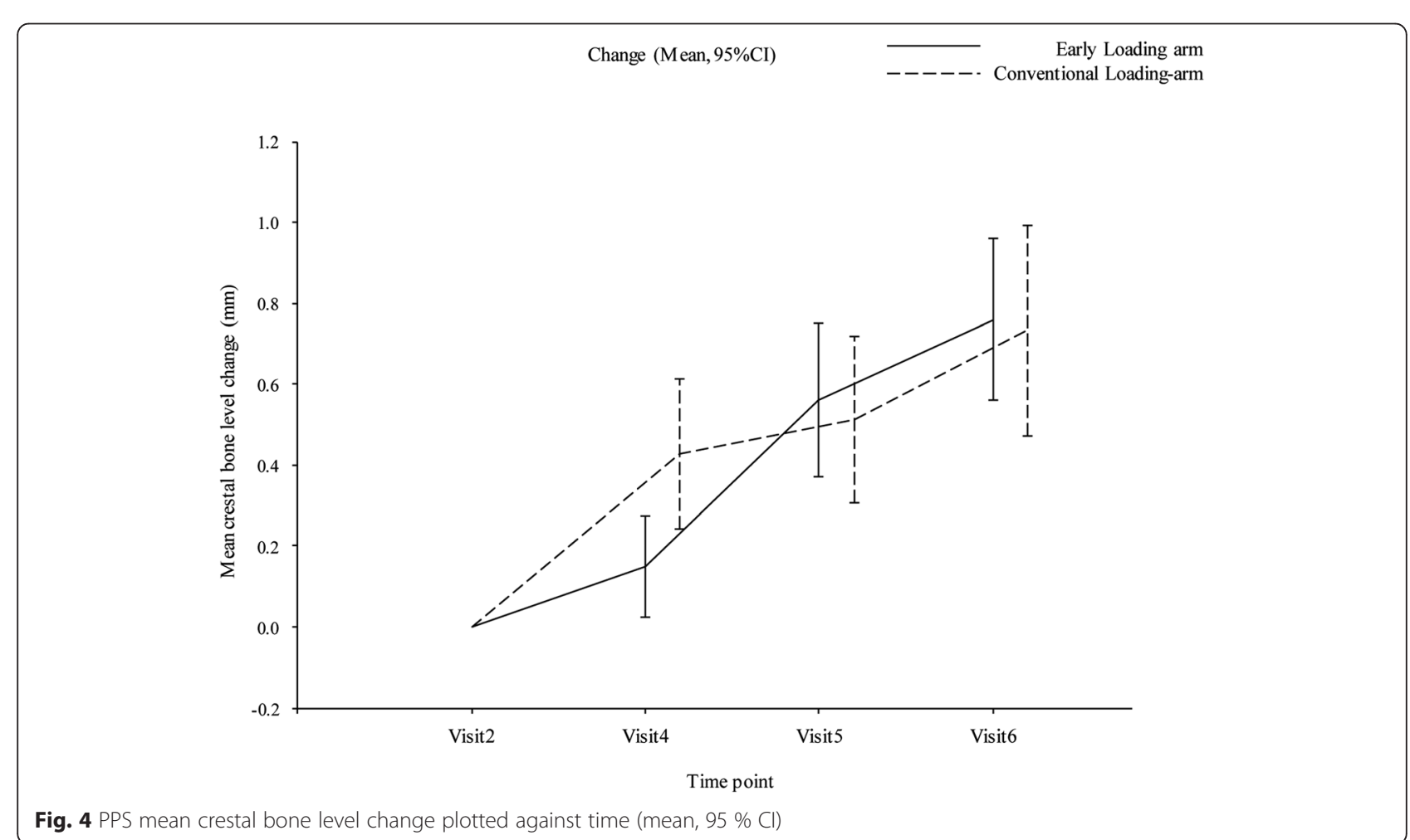


time point for loading was postponed. Finally, the implant treatments were also successful in these patients, hence the $100 \%$ success rate at follow-up. Survival was therefore "not evaluated" instead of "surviving," and success was "failed" instead of "successful" at 6 months.

\section{Efficacy evaluations: patient satisfaction}

Patients in both the PPS early and conventional loading arms at the 12-month follow-up generally rated their satisfaction in the indicators of prosthetic comfort, appearance, ability to taste, ability to chew, and general satisfaction as "satisfied" or "highly satisfied." However, for the satisfaction parameter of "fitting" (i.e., time take to occlusal loading after surgery), all patients in the early loading arm rated their satisfaction as either highly satisfied or satisfied (38 of 38 patients), while in the conventional loading arm only $78.4 \%$ of patients (29 of 37 ) gave the same rating (Table 5). The results for FAS were similar to those outlined above.

\section{Discussion}

This was a randomized, controlled, multicenter clinical trial to investigate whether the outcomes for chemically modified SLA implants in terms of change in crestal bone level from implant surgery to 6 months were noninferior with early loading ( $25 \pm 3$ days) compared to conventional loading (13 \pm 1 weeks). The difference in mean crestal bone level change between the early loading and conventional loading groups was $0.048 \mathrm{~mm}$
(95\% CI -0.227-0.322); non-inferiority of early loading was therefore confirmed within the parameters of the study. Therefore, null hypothesis was rejected.

Few randomized clinical trials are available showing the results of early loading with chemically modified SLA implants, and there are also relatively few prospective observational studies available [41, 42]. However, clinical studies have shown that successful osseointegration can be maintained and achieved for up to 3 years with these implants, with lower probing depth and clinical attachment level values compared to historical SLA controls [35, 43, 44]. Short implants with this surface have also shown high survival rates and good crestal bone levels after 2 years [37]. Early loading with SLA implants has been shown to be predictable, with excellent outcomes. Clinical data have shown that SLA implants can have very high success rates after 5 years following restoration after 6 weeks in type I to III bone and after 12 weeks in type IV bone, in both fully edentulous and partially edentulous patients and in both the mandible and maxilla [45-48], with stable crestal bone levels over 5 years [49]. Predictable early loading of SLA implants with maxillary full-arch prostheses [50] and mandibular overdentures [51] has also been observed.

The mean change in the bone level between baseline and 6 and 12 months of 0.561 and $0.760 \mathrm{~mm}$, respectively, for early loading was similar to that found in other clinical studies of early loading with chemically modified SLA (SLActive ${ }^{\circ}$ ) implants. For example, a mean change

Table 5 Patient satisfaction at 6 and 12 months, number of patients (\%)

\begin{tabular}{|c|c|c|c|c|c|c|c|c|c|c|c|c|c|}
\hline \multirow[b]{2}{*}{$\begin{array}{l}\text { Treatment } \\
\text { arm }\end{array}$} & \multirow{2}{*}{$\begin{array}{l}\text { Indicator } \\
\text { Timeline } \\
\text { (months) }\end{array}$} & \multicolumn{2}{|c|}{$\begin{array}{l}\text { Prosthetic } \\
\text { comfort }^{\mathrm{a}}\end{array}$} & \multicolumn{2}{|c|}{ Appearance $^{b}$} & \multicolumn{2}{|c|}{ Ability to chew ${ }^{c}$} & \multicolumn{2}{|c|}{ Ability to taste ${ }^{d}$} & \multicolumn{2}{|l|}{ Fitting $^{e}$} & \multicolumn{2}{|c|}{$\begin{array}{l}\text { General } \\
\text { satisfaction }^{\mathrm{f}}\end{array}$} \\
\hline & & 6 & 12 & 6 & 12 & 6 & 12 & 6 & 12 & 6 & 12 & 6 & 12 \\
\hline \multirow[t]{5}{*}{$\begin{array}{l}\text { Early loading } \\
N=38\end{array}$} & $\begin{array}{l}\text { Highly } \\
\text { satisfied }\end{array}$ & 12 (31.6) & $11(28.9)$ & $14(36.8)$ & $14(36.8)$ & $10(26.3)$ & 12 (31.6) & $11(28.9)$ & $16(42.1)$ & $11(28.9)$ & $9(23.7)$ & $14(36.8)$ & $14(36.8)$ \\
\hline & Satisfied & $25(65.8)$ & $26(68.4)$ & $22(57.9)$ & $24(63.2)$ & $26(68.4)$ & $24(63.2)$ & $25(65.8)$ & $21(55.3)$ & $25(65.8)$ & $29(76.3)$ & $23(60.5)$ & $24(63.2)$ \\
\hline & No opinion & $1(2.6)$ & $0(0.0)$ & $2(5.3)$ & $0(0.0)$ & $2(5.3)$ & $2(5.3)$ & $2(5.3)$ & $1(2.6)$ & $2(5.3)$ & $0(0.0)$ & $1(2.6)$ & $0(0.0)$ \\
\hline & Dissatisfied & $0(0.0)$ & $1(2.6)$ & $0(0.0)$ & $0(0.0)$ & $0(0.0)$ & $0(0.0)$ & $0(0.0)$ & $0(0.0)$ & $0(0.0)$ & $0(0.0)$ & $0(0.0)$ & $0(0.0)$ \\
\hline & $\begin{array}{l}\text { Highly } \\
\text { dissatisfied }\end{array}$ & $0(0.0)$ & $0(0.0)$ & $0(0.0)$ & $0(0.0)$ & $0(0.0)$ & $0(0.0)$ & $0(0.0)$ & $0(0.0)$ & $0(0.0)$ & $0(0.0)$ & $0(0.0)$ & $0(0.0)$ \\
\hline \multirow{5}{*}{$\begin{array}{l}\text { Conventional } \\
\text { loading } \\
N=37\end{array}$} & $\begin{array}{l}\text { Highly } \\
\text { satisfied }\end{array}$ & $14(37.8)$ & $13(35.1)$ & $14(37.8)$ & $12(32.4)$ & $11(29.7)$ & $14(37.8)$ & $17(45.9)$ & 18 (48.6) & $12(32.4)$ & $8(21.6)$ & $19(51.4)$ & $17(45.9)$ \\
\hline & Satisfied & $21(56.8)$ & $24(64.9)$ & $20(54.1)$ & $24(64.9)$ & $23(62.2)$ & $21(56.8)$ & $16(43.2)$ & 18 (48.6) & $16(43.2)$ & $21(56.8)$ & $17(45.9)$ & $19(51.4)$ \\
\hline & No opinion & $2(5.4)$ & $0(0.0)$ & $2(5.4)$ & $1(2.7)$ & $3(8.1)$ & $2(5.4)$ & $4(10.8)$ & $1(2.7)$ & $7(18.9)$ & $6(16.2)$ & $1(2.7)$ & $1(2.7)$ \\
\hline & Dissatisfied & $0(0.0)$ & $0(0.0)$ & $1(2.7)$ & $0(0.0)$ & $0(0.0)$ & $0(0.0)$ & $0(0.0)$ & $0(0.0)$ & $2(5.4)$ & $1(2.7)$ & $0(0.0)$ & $0(0.0)$ \\
\hline & $\begin{array}{l}\text { Highly } \\
\text { dissatisfied }\end{array}$ & $0(0.0)$ & $0(0.0)$ & $0(0.0)$ & $0(0.0)$ & $0(0.0)$ & $0(0.0)$ & $0(0.0)$ & $0(0.0)$ & $0(0.0)$ & $1(2.7)$ & $0(0.0)$ & $0(0.0)$ \\
\hline
\end{tabular}

${ }^{a}$ Does the patient have any uncomfortable feeling about the placed implant?

${ }^{b}$ What does the patient think about the prosthesis appearance?

'What does the patient think about chewing?

${ }^{d}$ Does the patient have any uncomfortable feeling about taste?

'What does the patient think about the time taken until occlusal loading was started after implantation surgery?

f Is the patient generally satisfied with the treatment result? 
in the bone level of $0.63 \pm 0.95 \mathrm{~mm}$ from baseline to 12 months was observed with early loading of implants with the chemically modified SLA surface in the posterior maxilla and mandible in a large prospective multicenter study [36]; after 3 years, the mean change in crestal bone level was $0.88 \pm 0.81 \mathrm{~mm}$, indicating minimal further bone loss beyond 12 months [38]. An earlier study of early loading with implants with the SLA surface showed a mean bone loss of $0.52 \pm 0.98 \mathrm{~mm}$ after 1 year, also in the posterior maxilla and mandible [52]. A threearm study of early loading of SLA implants in the edentulous posterior maxilla and mandible and completely edentulous maxilla showed a mean marginal bone loss of 0.75 $\pm 1.3 \mathrm{~mm}$ after 1 year [53], while a study of SLA implants in the posterior mandible showed mean crestal bone loss values of $0.57 \pm 0.49$ and $0.72 \pm 0.50 \mathrm{~mm}$ for early loading after 2 and 6 weeks, respectively, after 1 year [54].

The implant survival rate of $100 \%$ after 12 months is also in line with the results from previous studies with chemically modified SLA implants in various situations, including $100 \%$ survival in early loading of mandibular overdentures [55], $100 \%$ survival in single-tooth applications in the anterior maxilla [56], $96.8 \%$ with maxillary sinus floor augmentation [57], and 98 and $97 \%$ with immediate and early loading in posterior jaws [36], respectively. Excellent implant survival rates with early loading have also been achieved over longer time periods; for example, with chemically modified implants loaded after 21 days, $100 \%$ survival and success were observed over 3 years in the posterior mandible [35].

Implant survival rates in the current study also compare well with survival and success rates obtained for SLA implants over an equivalent period of time. For example, Al-Nawas and colleagues achieved implant survival rates of 96.9 and $96.4 \%$ for SLA implants loaded after 4 and 12 weeks, respectively [58], while Fischer and Stenberg achieved $100 \%$ survival with SLA implants supporting early-loaded maxillary full-arch prostheses [59]. It should be remembered, however, that the patients enrolled in the current study were treated by highly experienced implant surgeons and were subjected to strict inclusion and exclusion criteria, although high survival rates with these implants have also been found in daily dental practice $[60,61]$.

The study was performed because early loading protocols for dental implants in Japan are still relatively uncommon, even though early loading of dental implants has elsewhere been demonstrated to be a viable treatment option to restore esthetics and function to the patient in a timely manner $[12,15,16,45]$ and has shown advantages in terms of preservation of hard and soft tissues [14], as well as providing psychological benefits for the patient. Few clinical trials on early loading have been conducted in the Japanese population, and the authors speculate that this may indicate a more conservative approach to implant rehabilitation among Japanese dentists and implant surgeons. However, a recent prospective, multicenter, non-interventional analysis of Straumann bone level implants with the chemically modified SLA surface in daily dental practice indicated that conventional loading is still very much the norm in most countries. In this analysis, the authors found that of 1113 implants, $68.6 \%$ were loaded with a conventional loading protocol, while early loading was used in only $12.4 \%$ of cases [61]. Conventional loading is therefore still very much favored, despite evidence that there are no clinically important differences between the different loading protocols regarding implant or prosthesis failure $[12,62]$ or crestal bone loss $[12,15]$. It has been noted, however, that not all clinicians can achieve optimum results with early loading and that high primary implant stability may be a requirement for a successful procedure [62].

Early loading of the implants showed a good safety profile, with a similar incidence in AEs between the early and conventional loading groups. The benefits to the patient for the early loading procedure were demonstrated by the patient satisfaction question "What does the patient think about the time taken until occlusal loading was started after implantation surgery?" All patients in the early loading group were "satisfied" $(76.3 \%)$ or "highly satisfied" (23.7\%), compared with $78.4 \%$ of patients in the conventional loading group who were "satisfied" (56.8 \%) or "highly satisfied" (21.6 \%). Scores for the other categories of patient satisfaction were similar between the groups, corresponding to similar levels of patient satisfaction with early and conventional loading in other studies with single-tooth implant rehabilitation $[63,64]$.

The authors recognize that the study has certain limitations. For example, 6 months is a relatively short time for evaluation of a primary efficacy endpoint; generally, a minimum of 1 year is required for scientific validity in implant dentistry. Although the same evaluation as the primary efficacy endpoint (i.e., change in crestal bone level from baseline) was measured at 12 months, in retrospect, the change at 12 months should perhaps have been taken as a more clinically relevant primary efficacy endpoint. Increasingly, clinicians are calling for long-term evidence on dental implants and, as the time that implants have remained in situ in patients has increased over the years, more and more studies of 10, 15, and 20 years and over are being published and show high survival rates and low crestal bone loss $[6,65-71]$.

Since the softer bone in the maxilla may lead to a greater incidence of late implant failure [72], and therefore may require a longer loading protocol than the early loading protocol in this study [73], in retrospect, it may have been valid to evaluate the outcomes in the posterior maxilla and 
mandible separately. Similarly, because of the differences in ridge dimensions from premolar to molar sites in both jaws [74], a separate analysis of the crestal bone changes in these areas may have been applicable.

\section{Conclusions}

In conclusion, this study demonstrated that early implant loading was non-inferior to conventional implant loading in terms of crestal bone level change in a Japanese patient population in short follow-up period and single tooth gaps in molar regions. High implant survival and patient satisfaction rates, and a good safety profile, were also achieved.

\section{Competing interests}

Michel Dard, Makoto Shiota, Minoru Sanda, Yasutomo Yajima, Hideshi Sekine, and Shohei Kasugai state that there are no conflicts of interest.

\section{Authors' contributions}

MD mainly prepared the manuscript and figures. MS arranged this study, participated in its design and coordination, and helped to draft the manuscript. YY, HS, and SK managed the data collection from each centers of Tokyo Dental College Chiba Hospital (TDCC), Tokyo Dental College Suidobashi Hospital (TDCS), and Tokyo Medical and Dental University (TDMU), respectively. MS contributed by practical work for collecting the data. All authors read and approved the final manuscript.

\section{Acknowledgements}

This trial was sponsored by Straumann Japan KK. The authors would like to acknowledge the assistance of Eusaku Watanabe and Nariyuki Maezawa (both Straumann Japan KK) for their contributions to the study.

\section{Author details}

${ }^{1}$ College of Dentistry, New York University, New York, NY, USA. ${ }^{2}$ Tokyo Medical and Dental University, Tokyo, Japan. ${ }^{3}$ Suidobashi Hospital, Tokyo Dental College, Tokyo, Japan. ${ }^{4}$ School of Dentistry, Ohu University, Fukushima, Japan. ${ }^{5}$ Department of Oral Implantology and Regenerative Dental Medicine, Tokyo Medical and Dental University, 1-5-45 Yushima, Bunkyo-ku, Tokyo 113-8549, Japan.

Received: 25 September 2015 Accepted: 23 March 2016

Published online: 04 April 2016

\section{References}

1. Blanes RJ, Bernard JP, Blanes ZM, Belser UC. A 10-year prospective study of ITI dental implants placed in the posterior region. I: clinical and radiographic results. Clin Oral Implants Res. 2007:18:699-706.

2. Covani U, Chiappe G, Bosco M, Orlando B, Quaranta A, Barone A. A 10-year evaluation of implants placed in fresh extraction sockets: a prospective cohort study. J Periodontol. 2012;83:1226-34.

3. Misch CE, Misch-Dietsh F, Silc J, Barboza E, Cianciola LJ, Kazor C. Posterior implant single-tooth replacement and status of adjacent teeth during a 10-year period: a retrospective report. J Periodontol. 2008;79:2378-82.

4. Jemt T. Single implants in the anterior maxilla after 15 years of follow-up: comparison with central implants in the edentulous maxilla. Int J Prosthodont. 2008:21:400-8.

5. Astrand P, Ahlqvist J, Gunne J, Nilson H. Implant treatment of patients with edentulous jaws: a 20-year follow-up. Clin Implant Dent Relat Res. 2008;10:207-17.

6. Chappuis V, Buser R, Brägger U, Bornstein MM, Salvi GE, Buser D. Long-term outcomes of dental implants with a titanium plasma-sprayed surface: a 20-year prospective case series study in partially edentulous patients. Clin Implant Dent Relat Res. 2013:15:780-90.

7. Salinas TJ, Eckert SE. In patients requiring single-tooth replacement, what are the outcomes of implant- as compared to tooth-supported restorations? Int J Oral Maxillofac Implants. 2007;22(Suppl):71-95.

8. Torabinejad M, Anderson P, Bader J, et al. Outcomes of root canal treatment and restoration, implant-supported single crowns, fixed partial dentures, and extraction without replacement: a systematic review. J Prosthet Dent. 2007;98:285-311.

9. Koo KT, Wikesjö UM, Park JY, et al. Evaluation of single-tooth implants in the second molar region: a 5-year life-table analysis of a retrospective study. J Periodontol. 2010;81:1242-9.

10. Levin L, Laviv A, Schwartz-Arad D. Long-term success of implants replacing a single molar. J Periodontol. 2006;77:1528-32.

11. Morton D, Jaffin R, Weber HP. Immediate restoration and loading of dental implants: clinical considerations and protocols. Int J Oral Maxillofac Implants. 2004;19(Suppl):103-8.

12. Esposito M, Grusovin MG, Maghaireh H, Worthington HV. Interventions for replacing missing teeth: different times for loading dental implants. Cochrane Database of Syst Rev. 2013;3:CD003878.

13. Esposito M, Grusovin MG, Willings M, Coulthard P, Worthington HV. The effectiveness of immediate, early, and conventional loading of dental implants: a Cochrane systematic review of randomized controlled clinical trials. Int J Oral Maxillofac Implants. 2007:22(6):893-904.

14. Sanz I, Garcia-Gargallo M, Herrera D, et al. Surgical protocols for early implant placement in post-extraction sockets: a systematic review. Clin Oral Implants Res. 2012;23 Suppl 5:67-79.

15. Suarez F, Chan HL, Monje A, Galindo-Moreno P, Wang HL. Effect of the timing of restoration on implant marginal bone loss: a systematic review. J Periodontol. 2013;84:159-69.

16. Annibali S, Bignozzi I, Lacovazzi L, La Monaca G, Cristalli MP. Immediate, early, and late implant placement in first-molar sites: a retrospective case series. Int J Oral Maxillofac Implants. 2011;26:1108-22.

17. Mendonça G, Mendonça DB, Aragão FJ, Cooper LF. Advancing dental implant surface technology-from micron- to nanotopography. Biomaterials. 2008:29:3822-35.

18. Stanford CM. Surface modifications of dental implants. Aust Dent J. 2008:53 Suppl 1:S26-33.

19. Wennerberg A, Albrektsson T. On implant surfaces: a review of current knowledge and opinions. Int J Oral Maxillofac Implants. 2010;25:63-74.

20. Dohan Ehrenfest DM, Coelho PG, Kang BS, Sul YT, Albrektsson T. Classification of osseointegrated implant surfaces: materials, chemistry and topography. Trends Biotechnol. 2010;28:198-206.

21. Kim TI, Jang JH, Kim HW, Knowles JC, Ku Y. Biomimetic approach to dental implants. Curr Pharm Des. 2008:14:2201-11.

22. Morra M. Biomolecular modification of implant surfaces. Expert Rev Med Devices. 2007:4:361-72.

23. Buser D, Broggini N, Wieland M, et al. Enhanced bone apposition to a chemically modified SLA titanium surface. J Dent Res. 2004;83:529-33.

24. Schwarz F, Sager M, Ferrari D, Herten M, Wieland M, Becker J. Bone regeneration in dehiscence-type defects at non-submerged and submerged chemically modified (SLActive) and conventional SLA titanium implants: an immunohistochemical study in dogs. J Clin Periodontol. 2008:35:64-75.

25. Bornstein MM, Valderrama P, Jones AA, Wilson TG, Seibl R, Cochran DL. Bone apposition around two different sandblasted and acid-etched titanium implant surfaces: a histomorphometric study in canine mandibles. Clin Oral Implants Res. 2008;19:233-41.

26. Lai HC, Zhuang LF, Zhang ZY, Wieland M, Liu X. Bone apposition around two different sandblasted, large-grit and acid-etched implant surfaces at sites with coronal circumferential defects: an experimental study in dogs. Clin Oral Implants Res. 2009:20:247-53.

27. Ferguson SJ, Broggini N, Wieland M, et al. Biomedical evaluation of the interfacial strength of a chemically modified sandblasted and acid-etched titanium surface. J Biomed Mater Res A. 2006;78:291-7.

28. Schwarz F, Ferrari $D$, Herten $M$, et al. Effects of surface hydrophilicity and microtopography on early stages of soft and hard tissue integration at nonsubmerged titanium implants: an immunohistochemical study in dogs. J Periodontol. 2007:78:2171-84.

29. Schwarz F, Herten M, Sager M, Wieland M, Dard M, Becker J. Bone regeneration in dehiscence-type defects at chemically modified (SLActive) and conventional SLA titanium implants: a pilot study in dogs. J Clin Periodontol. 2007:34:78-86.

30. Lang NP, Salvi GE, Huynh-Ba G, Ivanovski S, Donos N, Bosshardt DD. Early osseointegration to hydrophilic and hydrophobic implant surfaces in humans. Clin Oral Implants Res. 2011;22:349-56.

31. Schätzle M, Männchen R, Balbach U, Hämmerle $\mathrm{CH}$, Toutenburg H, Jung RE. Stability change of chemically modified sandblasted/acid-etched titanium 
palatal implants. A randomized-controlled clinical trial. Clin Oral Implants Res. 2009:20:489-95.

32. Oates TW, Valderrama P, Bischof M, et al. Enhanced implant stability with a chemically modified SLA surface: a randomized pilot study. Int J Oral Maxillofac Implants. 2007;22:755-60.

33. Cochran DL, Buser D, ten Bruggenkate $C M$, et al. The use of reduced healing times on ITI implants with a sandblasted and acid-etched (SLA) surface: early results from clinical trials on ITI SLA implants. Clin Oral Implants Res. 2002;13:144-53.

34. Cochran D, Oates T, Morton D, Jones A, Buser D, Peters F. Clinical field trial examining an implant with a sand-blasted, acid-etched surface. J Periodontol. 2007;78:974-82.

35. Bornstein MM, Wittneben JG, Brägger U, Buser D. Early loading at 21 days of non-submerged titanium implants with a chemically modified sandblasted and acid-etched surface: 3 -year results of a prospective study in the posterior mandible. J Periodontol. 2010;81:809-18.

36. Ganeles J, Zöllner A, Jackowski J, ten Bruggenkate C, Beagle J, Guerra F. Immediate and early loading of Straumann implants with a chemically modified surface (SLActive) in the posterior mandible and maxilla: 1-year results from a prospective multicenter study. Clin Oral Implants Res. 2008;19:1119-28.

37. Rossi F, Ricci E, Marchetti C, Lang NP, Botticelli D. Early loading of single crowns supported by 6-mm-long implants with a moderately rough surface: a prospective 2-year follow-up cohort study. Clin Oral Implants Res. 2010;21:937-43.

38. Nicolau P, Korostoff J, Ganeles J, et al. Immediate and early loading of chemically modified implants in posterior jaws: 3-year results from a prospective randomized multicenter study. Clin Implant Dent Relat Res. 2013;15:600-12.

39. Efird J. Blocked randomization with randomly selected block sizes. Int J Environ Res Public Health. 2011:8(1):15-20.

40. Buser D, Weber HP, Lang NP. Tissue integration of non-submerged implants. 1-year results of a prospective study with 100 ITI hollow-cylinder and hollow-screw implants. Clin Oral Implants Res. 1990;1:33-40.

41. Bornstein MM, Hart CN, Halbritter SA, Morton D, Buser D. Early loading of nonsubmerged titanium implants with a chemically modified sand-blasted and acid-etched surface: 6-month results of a prospective case series study in the posterior mandible focusing on peri-implant crestal bone changes and implant stability quotient (ISQ) values. Clin Implant Dent Relat Res. 2009;11:338-47.

42. Chambrone L, Shibli JA, Mercúrio CE, Cardoso B, Preshaw PM. Efficacy of standard (SLA) and modified sandblasted and acid-etched (SLActive) dental implants in promoting immediate and/or early occlusal loading protocols: a systematic review of prospective clinical studies. Clin Oral Implants Res. 2014. doi:10.1111/dr.12347.

43. Marković A, Colić S, Sćepanović M, Mišić T, Ethinić A, Bhusal DS. A 1-year prospective clinical and radiographic study of early-loaded bone level implants in the posterior maxilla. Clin Implant Dent Relat Res. 2014. doi:10.1111/cid.12201.

44. Morton D, Bornstein MM, Wittneben JG, et al. Early loading after 21 days healing of nonsubmerged titanium implants with a chemically modified sandblasted and acid-etched surface: two-year results of a prospective twocenter study. Clin Implant Dent Relat Res. 2010;12:9-17.

45. Cochran DL, Jackson JM, Bernard JP, et al. A 5-year prospective multicenter study of early loaded titanium implants with a sandblasted and acid-etched surface. Int J Oral Maxillofac Implants. 2011;26:1324-32.

46. Lethaus B, Kälber J, Petrin G, Brandstätter A, Weingart D. Early loading of sandblasted and acid-etched titanium implants in the edentulous mandible: a prospective 5-year study. Int J Oral Maxillofac Implants. 2011;26:887-92.

47. Roccuzzo M, Aglietta M, Bunino M, Bonino L. Early loading of sandblasted and acid-etched implants: a randomized-controlled double-blind splitmouth study. Five-year results. Clin Oral Implants Res. 2008;19:148-52.

48. Roccuzzo M, Wilson T. A prospective study evaluating a protocol for 6 weeks' loading of SLA implants in the posterior maxilla: one year results. Clin Oral Implants Res. 2002;13:502-7.

49. Bornstein MM, Schmid B, Belser UC, Lussi A, Buser D. Early loading of nonsubmerged titanium implants with a sandblasted and acid-etched surface. 5year results of a prospective study in partially edentulous patients. Clin Oral Implants Res. 2005;16:631-8.

50. Lai HC, Zhang ZY, Zhuang LF, Wang F, Liu X, Pu YP. Early loading of ITI implants supporting maxillary full-arch prostheses. Clin Oral Implants Res. 2008;19:1129-34.

51. Payne AG, Tawse-Smith A, Duncan WD, Kumara R. Conventional and early loading of unsplinted ITI implants supporting mandibular overdentures. Clin Oral Implants Res. 2002;13:603-9.

52. Luongo G, Di Raimondo R, Filippini P, Gualini F, Paoleschi C. Early loading of sandblasted, acid-etched implants in the posterior maxilla and mandible: a 1-year follow-up report from a multicenter 3-year prospective study. Int J Oral Maxillofac Implants. 2005;20:84-91.
53. Nordin T, Nilsson R, Frykholm A, Hallman M. A 3-arm study of early loading of rough-surfaced implants in the completely edentulous maxilla and in the edentulous posterior maxilla and mandible: results after 1 year of loading. Int J Oral Maxillofac Implants. 2004;19:880-6.

54. Salvi GE, Gallini G, Lang NP. Early loading ( 2 or 6 weeks) of sandblasted and acid-etched (SLA) ITI implants in the posterior mandible. A 1-year randomised controlled clinical trial. Clin Oral Implants Res. 2004;15:142-9.

55. El-Sheikh AM, Shihabuddin OF, Ghoraba SM. A prospective study of early loaded single implant-retained mandibular overdentures: preliminary oneyear results. Int J Dent. 2012. doi: 10.1155/2012/236409.

56. Furze D, Byrne A, Donos N, Mardas N. Clinical and esthetic outcomes of singletooth implants in the anterior maxilla. Quintessence Int. 2012;43:127-34.

57. Lindgren C, Mordenfeld A, Hallmann M. A prospective 1-year clinical and radiographic study of implants placed after maxillary sinus floor augmentation with synthetic biphasic calcium phosphate or deproteinized bovine bone. Clin Implant Dent Relat Res. 2012;14:41-50.

58. Al-Nawas B, Krummenauer F, Büchter A, et al. Multicenter randomized clinical trial: early loading of implants in maxillary bone. Clin Implant Dent Relat Res. 2013;15:625-36.

59. Fischer K, Stenberg T. Early loading of ITI implants supporting a maxillary full-arch prosthesis: 1-year data of a prospective, randomized study. Int J Oral Maxillofac Implants. 2004;19:374-81.

60. Luongo G, Oteri G. A noninterventional study documenting use and success of implants with a new chemically modified titanium surface in daily dental practice. J Oral Implantol. 2010;36:305-14.

61. Filippi A, Higginbottom FL, Lambrecht T, et al. A prospective noninterventional study to document implant success and survival of the Straumann Bone Leve SLActive dental implant in daily dental practice. Quintessence Int. 2013;44:499-512.

62. Eliyas S, Al-Khayatt AS. No difference between failure rates of early and conventionally loaded implants. Evid Based Dent. 2008;9:50.

63. Schropp L, Isidor F. Clinical outcome and patient satisfaction following fullflap elevation for early and delayed placement of single-tooth implants: a 5year randomized study. Int J Oral Maxillofac Implants. 2008;23:733-43.

64. Knoernschild KL. Early survival of single-tooth implants in the esthetic zone may be predictable despite timing of implant placement or loading. J Evid Based Dent Pract. 2012;12:209-12.

65. Krebs M, Schmenger K, Neumann K, Weigl P, Moser W, Nentwig GH. Longterm evaluation of ANKYLOS ${ }^{\otimes}$ dental implants, part I: 20-year life table analysis of a longitudinal study of more than 12,500 implants. Clin Implant Dent Relat Res. 2013. doi:10.1111/cid.12154.

66. Lops D, Bressan E, Pisoni G, Cea N, Corazza B, Romeo E. Short implants in partially edentulous maxillae and mandibles: a 10 to 20 years retrospective evaluation. Int J Dent. 2012. doi:10.1155/2012/351793.

67. Misje K, Bjørnland T, Saxegaard E, Jensen JL. Treatment outcome of dental implants in the esthetic zone: a 12- to 15 -year retrospective study. Int J Prosthodont. 2013;26:365-9.

68. Mordenfeld A, Albrektsson T, Hallman M. A 10-year clinical and radiographic study of implants placed after maxillary sinus floor augmentation with an 80:20 mixture of deproteinized bovine bone and autogenous bone. Clin Implant Dent Relat Res. 2014;16:435-46.

69. Östman PO, Hellman M, Sennerby L. Ten years later. Results from a prospective single-centre clinical study on 121 oxidized (TiUnite ${ }^{T M}$ ) Brånemark implants in 46 patients. Clin Implant Dent Relat Res. 2012;14:852-60.

70. Ravald N, Dahlgren S, Teiwik A, Gröndahl K. Long-term evaluation of Astra Tech and Brånemark implants in patients treated with full-arch bridges. Results after 12-15 years. Clin Oral Implants Res. 2013;24:1144-51.

71. Turkyilmaz I, Ozan O, Yilmaz B, Ersoy AE. Determination of bone quality of 372 implant recipient sites using Hounsfield unit from computerized tomography: a clinical study. Clin Implant Dent Relat Res. 2008;10:238-44.

72. Carr AB. Implant location and radiotherapy are the only factors linked to 2year implant failure. J Evid Based Dent Pract. 2012;12(3 Suppl):217-9.

73. lezzi G, Degidi M, Scarano A, Perrotti V, Piattelli A. Bone response to submerged, unloaded implants inserted in poor bone sites: a histological and histomorphometrical study of 8 titanium implants retrieved from man. J Oral Implantol. 2005:31:225-33.

74. Pramstraller M, Farina R, Franceschetti G, Pramstraller C, Trombelli L. Ridge dimensions of the edentulous posterior maxilla: a retrospective analysis of a cohort of 127 patients using computerized tomography data. Clin Oral Implants Res. 2011;22:54-61. 